\title{
ENGINEERING GEOLOGICAL CONDITIONS OF THESSALONIKI BASIN FOR UNDERGROUND WORKS
}

\author{
Kokkala A. ${ }^{1}$ and Marinos V. ${ }^{1}$ \\ ${ }^{1}$ Aristotle University of Thessaloniki, Department of Geology, 54124, Thessaloniki, Greece, \\ kokkalaa@geo.auth.gr,marinosv@geo.auth.gr
}

\begin{abstract}
The design and construction of underground works in an urban environment, face several geological challenges. The construction of a well-structured database, able to store, manage, analyse and correlate a large amount of geological and geotechnical data, is a powerful tool towards the geological hazard assessment and the geotechnical characterisation of the formations along a tunnel. The data processed by the database are based on borehole geological information, laboratory testing, geotechnical characterisation and in situ field tests, mainly executed in the quaternary and neogene soil formations that are met along the studied area. The processing and assessment of the information, leads to the identification of useful value ranges for several physical and mechanical parameters. The study also focuses in specific areas within the basin of Thessaloniki, highlighting the in situ conditions, by the construction of longitudinal profiles. The purpose of that process, besides incorporating new data, is to provide a tool for turning data into useful information in order to estimate the geological situation and geotechnical behavior of formations in underground works.
\end{abstract}

Keywords: Tunnel database, geotechnical parameters, quaternary and neogene deposits, mechanized tunneling.

\section{Пєрí $\eta \psi \eta$}

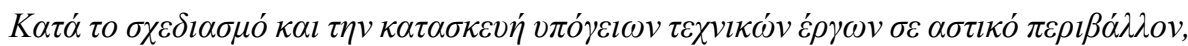

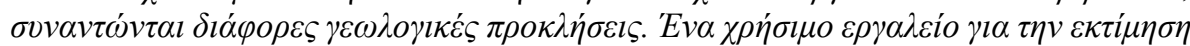

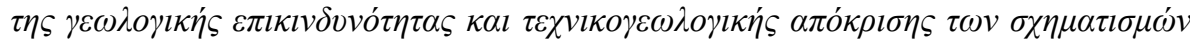

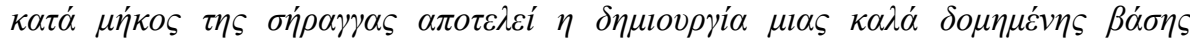

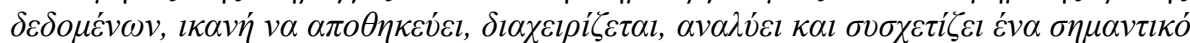

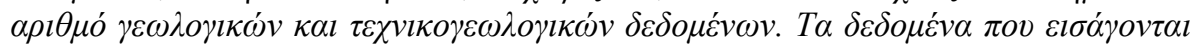

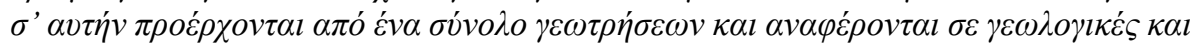

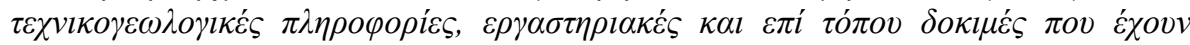

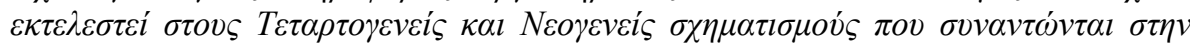

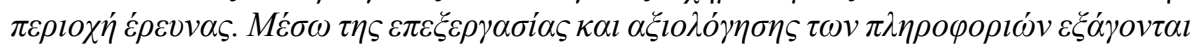

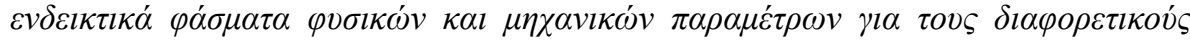

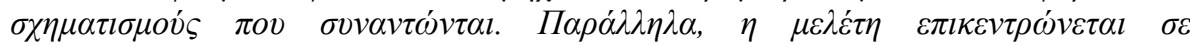

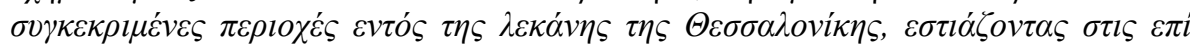

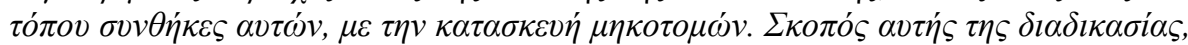

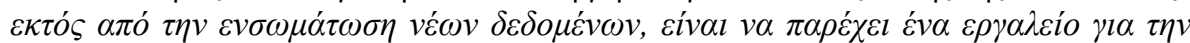

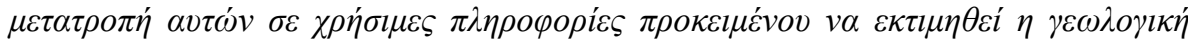

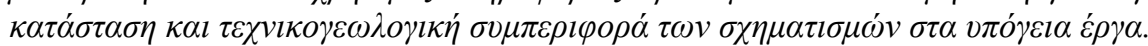

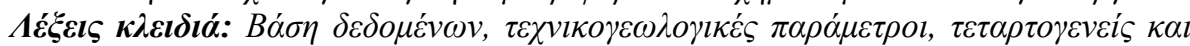

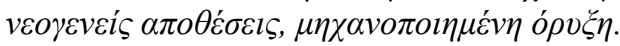




\section{Introduction}

In the last few decades rapid development in many levels of geotechnical design in urban areas can be discerned. This paper refers to the creation and evaluation of an engineering geological database for Thessaloniki basin with tunnel applications. The content of database regards to geological and geotechnical conditions and properties that are met in Thessaloniki basin, the second largest urban area after Athens, located in Northern Greece. Transportation problems are common in the center of the city. In such a context is under construction the metropolitan railway. At the same time, in the future is expected to be observed a continuous advancement of tunneling not only with the construction of the extensions of metro, but with a general development of underground structures.

The geology of the urban area of Thessaloniki is characterized by the presence of Neogene and Quaternary deposits. Neogene deposits consists of Red clays series and Sandstone-marl series. Red clay series composed of stiff to hard clays. The components of Sandstone-marl series are silty to clayey sand and sandy clay to sandy silt with presence of fine to medium gravels. Quaternary deposits consist mainly of sands, clays, gravel, and local presences of conglomerates.

All geological information including geotechnical data from 200 boreholes that were provided from «Central Laboratory of Public Works», «Geognosi» S.A. and Thessaloniki Metro, («Attiko Metro» S.A.), were stored in a database system. That database is based on Tunnel Information and Analysis System (TIAS) constructed for the Egnatia Highway tunnels in northern Greece (Marinos et al., 2013). More explicitly, the data entered and evaluated by the database come from geological and geotechnical information that based on a large amount of laboratory and in situ field tests.

In order to achieve this scope, the following stages were processed:

- Collection of all relevant data from studies, surveys, and task reports

- Selection, classification and evaluation of data regarding their credibility and utility

- Data entry in database

- Analyses and correlations of the processed data

- Identification of useful value ranges for several parameters, assigned for different formations

- Construction of geotechnical longitudinal profiles for specific areas

- Estimation of tunnel behavior of specific formations

- Selection of a suitable tunneling boring machine

The processing and evaluation of that information lead, through a set of procedures, to the assessment of geological situation and determination of geotechnical behavior of the formations in the underground works. As it is perceived the paper focuses additionally on the methodology for the classification of geological and geotechnical data for engineering geological purposes with respect to mechanized tunneling. The scope of this study is based on the work of Marinos et al. (2008) for the evaluation of the geological and geotechnical conditions of Thessaloniki metro. For this purpose, new data from many additional boreholes have been added in order to expand and enrich the existing published study.

\section{Engineering geological database}

\subsection{Database}

\subsubsection{TIAS Database}

The present databased has been based in the Tunnel Information and Analysis System (TIAS), a database constructed for the Egnatia Highway tunnels in northern Greece. It is an integrated 
information system that consists of the database and management software which provides the user to analyse and process geological and geotechnical data, especially focused for underground works. TIAS is a well-structured database which allows the user to have accurate information for the description of the individual data (Marinos et al., 2013).

\subsubsection{Description of the database}

The database is a collection of distinct geological, geotechnical and tunnel data based in a hierarchical mode, which is stored in tables. Each database uses a specific way that describes the structure and relationships of the tables and all the entries have their own identity within the database. That means that at any time, data may be divided in accordance with the field in which they are registered. The structure of the database provides an unambiguous and continuous connection of all the distinct data.

The database constitutes the central core of that process as all the data are imported, analyzed and correlated relating to the underground works in the studied area. The data processed by the database are based on borehole geological information, laboratory testing, geotechnical characterisation and in situ field tests. The present database includes thirteen tables of input data. These data refer to general and detailed geological description, in situ permeability tests, groundwater level, standard penetration tests and results from laboratory tests such as particle size distribution, physical and mechanical properties from uniaxial, triaxial and shear box tests.

\section{Engineering geological conditions}

\subsection{Geology of research area}

The wider area of Thessaloniki, belongs geologically to the geotectonic zone of Perirodopiki. The urban area of Thessaloniki is founded partly on bedrock, and partly in post-alpine sediments. In detail, the bedrock consists of a Mesozoic green schist-gneiss complex that outcrops north-northeast of the city, probably due to the presence of near vertical normal faults. This complex is overlain by an Upper Miocene-Lower Pliocene sedimentary sequence. On the basis of that sequence observed the Red clays series consisting of stiff to hard clays. The formation that follows is known as Sandstone marl series and it consists of silty to clayey sand with presence of fine to medium gravels.

Quaternary formations cover the Neogene deposits throughout the largest part of the city and almost the entire historical centre. That formation acquires a significant thickness and consists mainly of sands, clays, gravel, and local presence of conglomerates.

Neogene and Quaternary deposits are covered in places by the fill deposits created in different phases of the historical development of the city. It is pointed out the presence of recent artificial anthropogenic fill, the thickness of which increases as approaching the coastline.

\subsection{Analysis and evaluation of ground data}

The aim of this study is to evaluate the geotechnical conditions for every formation of the research area. For this purpose, data from 200 boreholes were used and executed from 1963 to 2006, covering a large period of time. Identical process was carried out focusing on specific areas of Thessaloniki basin. The selected areas are located in the eastern and the central part of the city respectively.

Figure 1 shows the Engineering-geological map of the wider Thessaloniki area according to Rozos et al. (1998). It is emphasized that the initial form of this map does not include the Quaternary deposits and identified from the data boreholes in the Eastern area. 


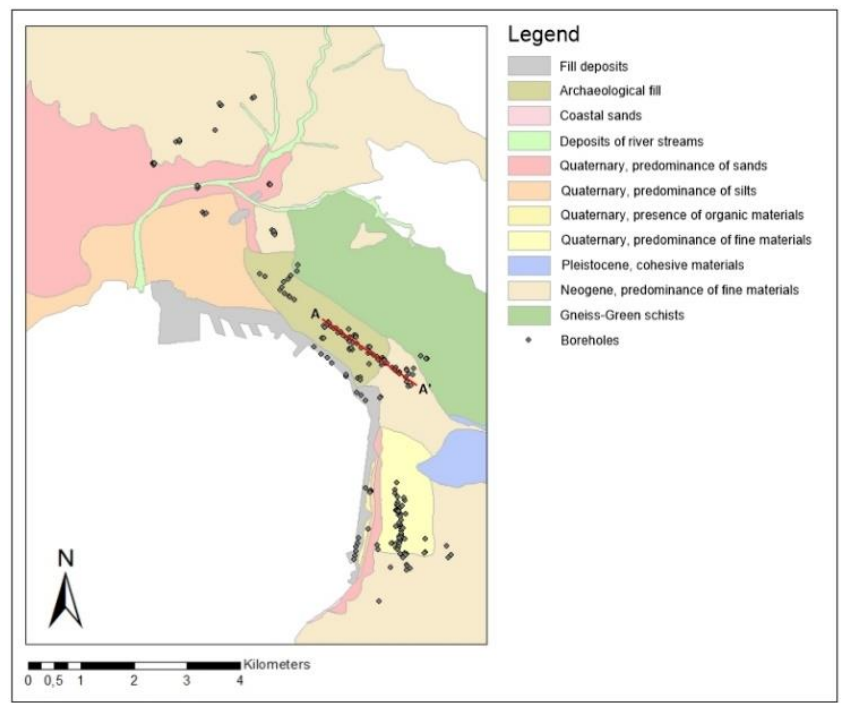

Figure 1 - Engineering-geological map of Thessaloniki city (modified by the authors from Rozos et al., 1998).

In the framework of this study, the data of the central part of Thessaloniki were selected to be analysed and presented (Figure 2). The parameters that were evaluated in this study are standard penetration tests (SPT), uniaxial compressive strength (qu), Atterberg limits, groundwater level, permeability tests and particle size analyses. The results of these analyses are presented mainly in the form of statistical distributions, charts and longitudinal profiles.

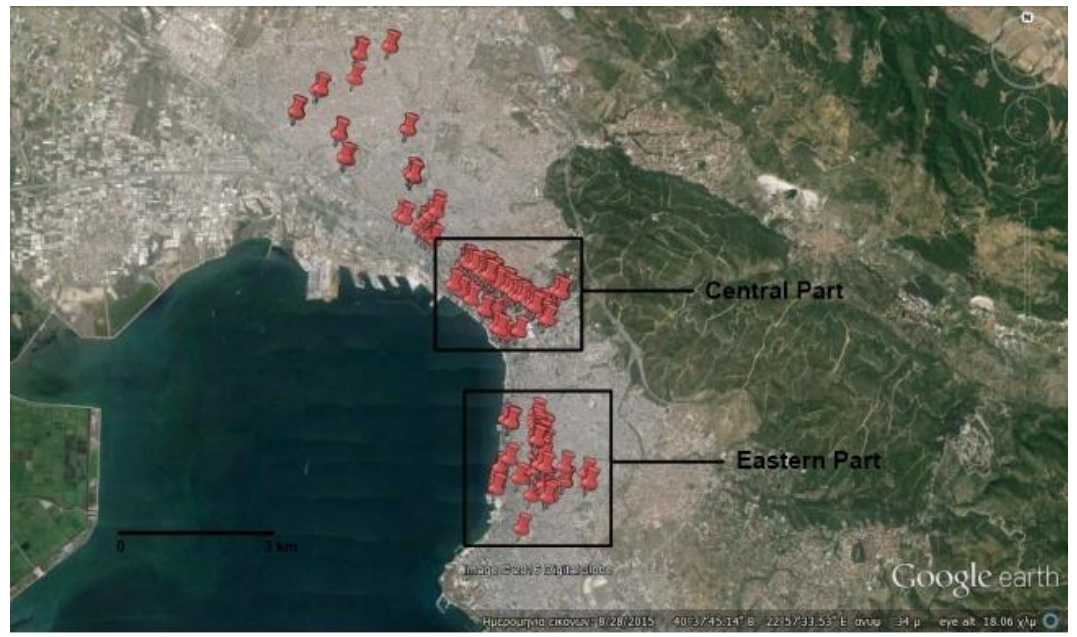

Figure 2 - Map of Thessaloniki city, showing the studied areas. In the paper, the central part is analysed (Google Earth).

\subsubsection{Geological-geotechnical ground model}

According to the longitudinal profile of the central part (Figure 1 and Figure 3), Neogene deposits prevail in small depth in relation to the Quaternary. More explicitly, Red clays of the Neogene deposits are composed mainly of clay. However, pockets with of coarser materials are observed.

Quaternary deposits consist of sandy and clayey materials. The range of these sediments is limited in both depth and length. The existence of old streams in these areas is associated with the position and structure of that formation. 
Fill deposits, are observed throughout the length of the area. An archaeological layer in the area of the historical center of the city exists with a variable thickness (up to $12 \mathrm{~m}$ ). As a result, these areas are particularly hazardous as regards to their geotechnical response.

As demonstrated at Figure 3, the fine-grained fraction of clays and silts is predominant along and around the studied area. However, there are areas, where deposits with coarser particle size might be encountered.

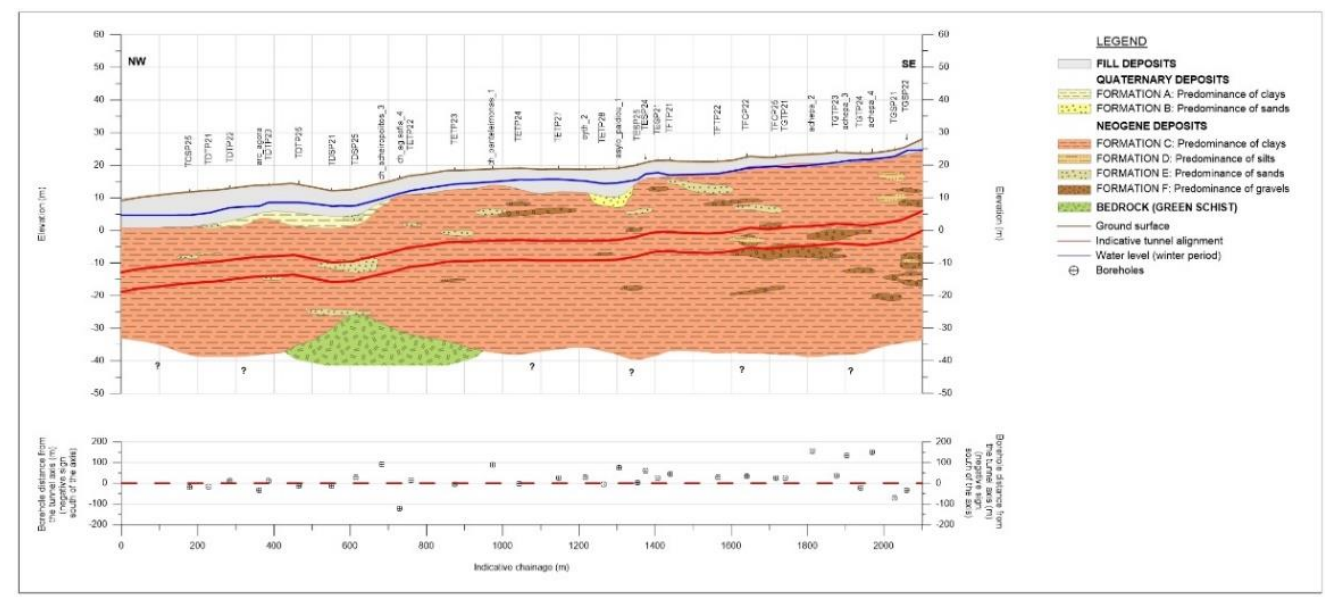

Figure 3 - Detailed geological longitudinal profile (NW-SE) for the Central part (the direction of the section is shown is Figure 1).

\subsubsection{Evaluation of Standard Penetration Tests}

Except for the longitudinal profile that was constructed for the central section, showing the distribution and prevalence of the formations, it is also necessary to evaluate the SPT values and permeability tests with depth along the selected area.

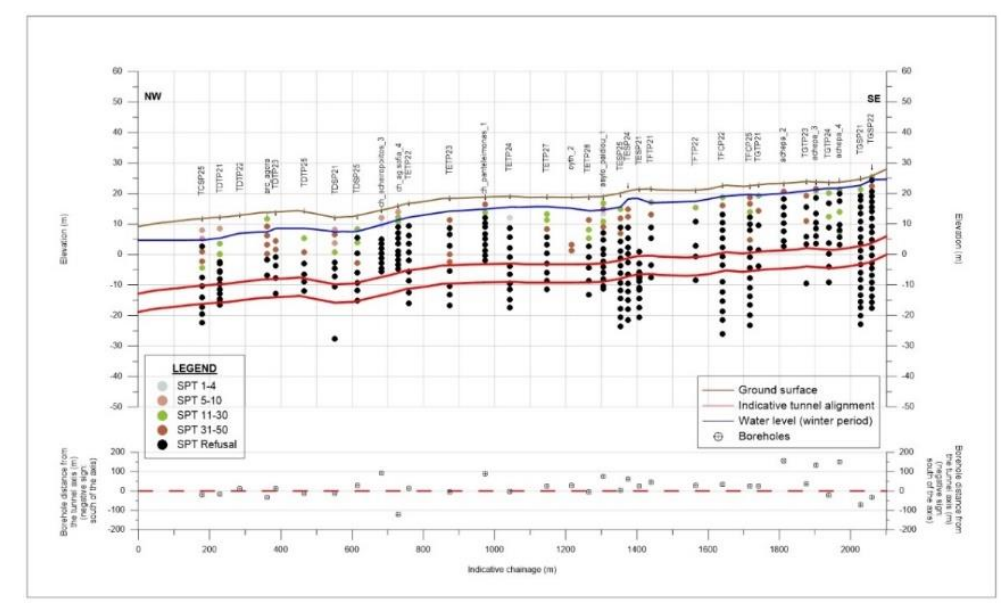

Figure 4 - SPT value distribution graph along the area of the alignment, for the Central part of the studied area.

The standard penetration tests that were assessed for this particular section are illustrated in Figure 4. The total number of tests amounts to 331. The results of the SPT were categorized in five classes: $\mathrm{N}_{\mathrm{SPT}}<1,5<N_{\mathrm{SPT}}<10,11<N_{\mathrm{SPT}}<30,31<N_{\mathrm{SPT}}<50 \kappa \alpha \mathrm{N}_{\mathrm{SPT}}>50$ (refusal).

Along the profile, different values of SPT were observed, from very low to refusals. Almost $76 \%$ of the values showed refusals, while approximately $2 \%$ showed values of less than 10 . The refusals 
were observed entirely within the Neogene deposits, while the smaller values of SPT in the overburden and mostly within the Quaternary and fill deposits.

At shallow depths, in the area between chainage $0+150$ and $0+700$, as well as in the area between chainage $1+050$ and $1+350$ are mainly small values $(<30)$. These values are met at Quaternary sediments and at maximum depths of fill deposits. Local, can be observed greater values (31-50).

Refusals dominate along the entire profile, within Neogene deposits. These values are observed at various depths, hence giving to that formation very high resistance. It is pointed out that a tunnel in $15-30 \mathrm{~m}$ depth passes overall in the Neogene formations where only refusals prevail.

\subsubsection{Evaluation of in situ permeability tests}

The in situ permeability tests that were assessed for this particular section are illustrated in Figure 5. The total number of tests amounts to 111 . The results of the tests were categorised in five classes: $\mathrm{k}<10^{-7} \mathrm{~m} / \mathrm{sec}, 10^{-7} \mathrm{~m} / \mathrm{sec}<=\mathrm{k}<10^{-6} \mathrm{~m} / \mathrm{sec}, 10^{-6} \mathrm{~m} / \mathrm{sec}<=\mathrm{k}<10^{-5} \mathrm{~m} / \mathrm{sec}, 10^{-5} \mathrm{~m} / \mathrm{sec}<=\mathrm{k}<10^{-4} \mathrm{~m} / \mathrm{sec}$ $\kappa \alpha \mathrm{k}>10^{-4} \mathrm{~m} / \mathrm{sec}$.

For this purpose, Maag and Lugeon tests were carried out. The prevalence of Maag tests (99) is notable, due to the strong presence of fine grained soil materials. Lugeon tests (12) were executed in various formations such as marl, sandstone, breccia and formations that can be characterized as soft rocks or hard soils.

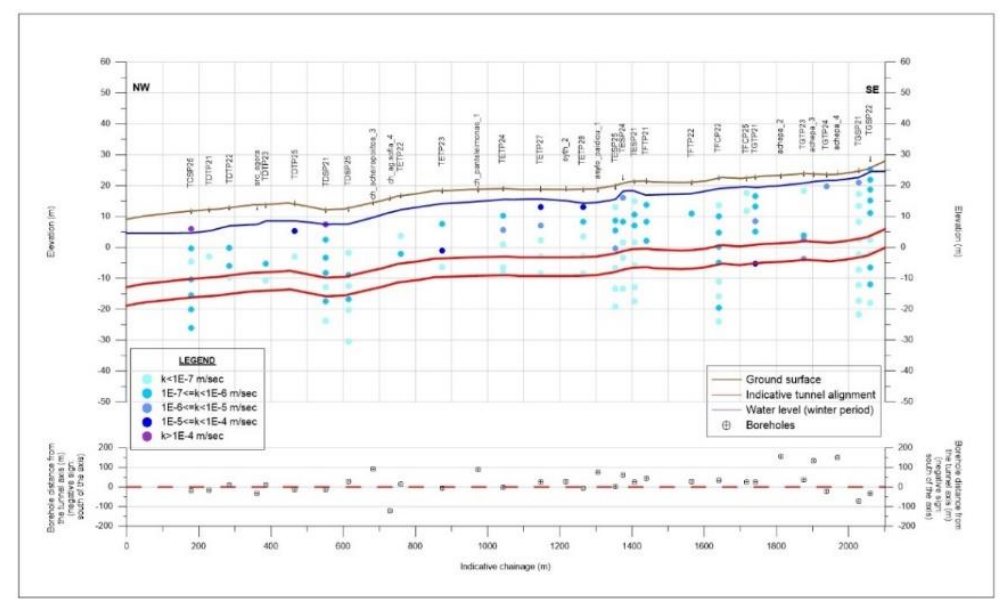

Figure 5 - Permeability distribution graph along the area of the alignment, for the Central part of the studied area.

Along the profile, various values of hydraulic conductivity were observed, indicating formations of different permeability. Specifically, $94 \%$ of the measurements showed values less than $10^{-5} \mathrm{~m} / \mathrm{sec}$, whereas only $6 \%$ showed values greater than $10^{-5} \mathrm{~m} / \mathrm{sec}$.

It is mentioned that at the greatest depths the values of hydraulic conductivity are restricted under $10^{-6} \mathrm{~m} / \mathrm{sec}$.

However, greater values $\left(\mathrm{k}>=10^{-5} \mathrm{~m} / \mathrm{sec}\right)$ are observed relatively at shallow depths, up to $15 \mathrm{~m}$ depth. These values are individual, they have been observed in certain boreholes and do not present a wide spread. The increased permeability is due to the presence of coarser materials. 


\subsubsection{Uniaxial Compressive Strength}

The values of uniaxial compressive strength of the Neogene deposits of central part are illustrated at Figure 6 . The majority of the measurements range between 0,25 and $1 \mathrm{MPa}$. These values indicate a stable to stiff formation.

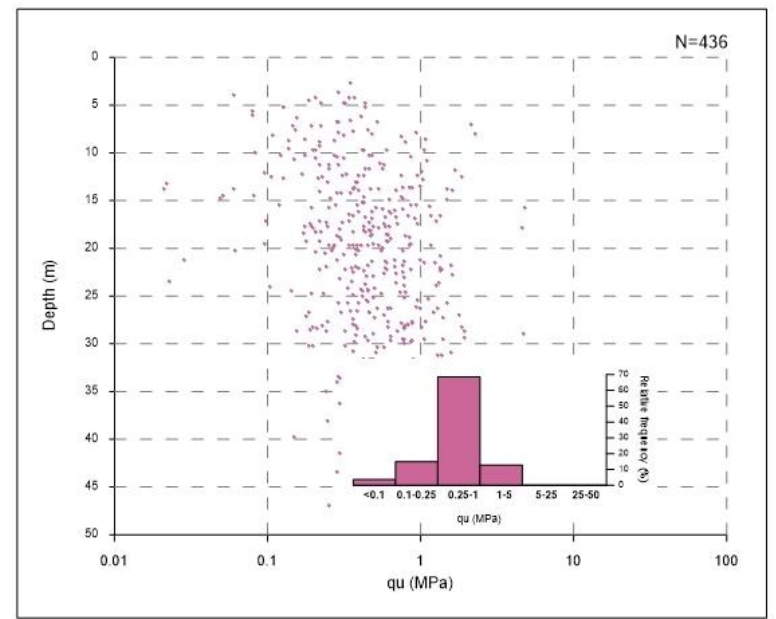

Figure 6 - Distribution charts of uniaxial compressive strength (qu) values for the Neogene deposits of the Central part of the studied area.

\subsubsection{Atterberg limits}

The results of Atterberg limits for the Neogene deposits of the central part are illustrated in Figure 7. Taking account, the Liquid Limit, it is estimated that the majority of measurements are low to medium values of plasticity, less than 50. As regard to the Plasticity Index, it is estimated that these materials are characterized by medium to high index of plasticity. These values range between 7 and 17 (39\%) and mainly between 17 to $35(58 \%)$.
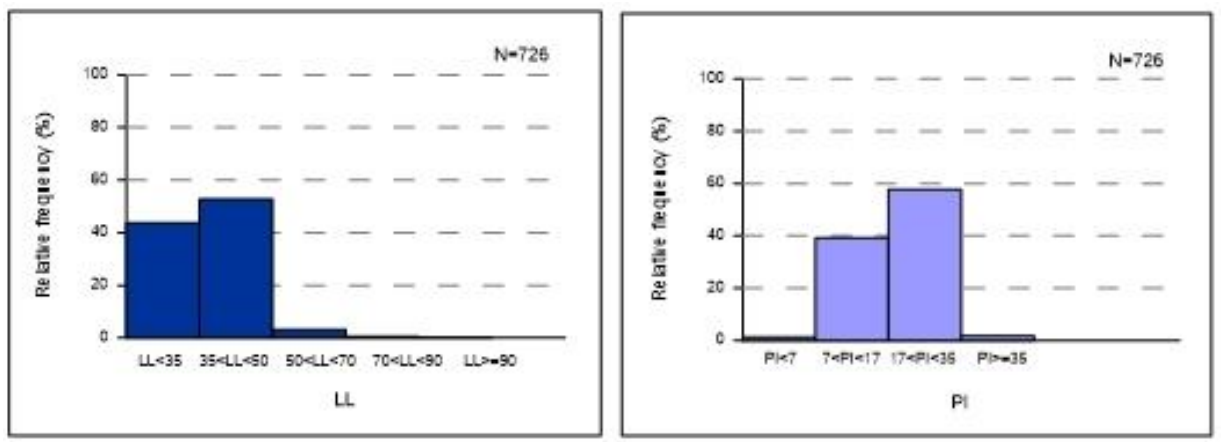

Figure 7 - Distribution charts of Atterberg limits (LL, PI) for the Neogene deposits of the Central part.

\subsection{Considerations on TBM selection}

The construction of underground works in the urban area of Thessaloniki requires the prediction of the behaviour of the formations during the excavation. Particular emphasis should be given to the selection of the appropriate TBM machine in order to minimise the settlements induced at the surface. There are two main types of machines that exhibit this feature and utilise a face support system. 
These are the Earth Pressure Balance machine (EPBM) and the Slurry Shield machine (Slurry TBM) (Geodata S.p.a., 2008).

However, the selection of the appropriate machine should also take into account the characteristics and parameters of formations. These are analysed below and referred to particle-size analysis, permeability and sticky behaviour of soils (Marinos et al., 2008).

\subsubsection{Particle-Size Analysis}

Figure 8 shows the grading envelopes of Neogene deposits of central part. These envelopes are examined in terms of suitability for each type of TBM (EPB or Slurry machine). The majority of the soil curves shows a high percentage of fines. According to the diagram the formations consist of sandy clays and clays with sand, sandy silts and clayey to silty sands with a variable percentage of gravels.

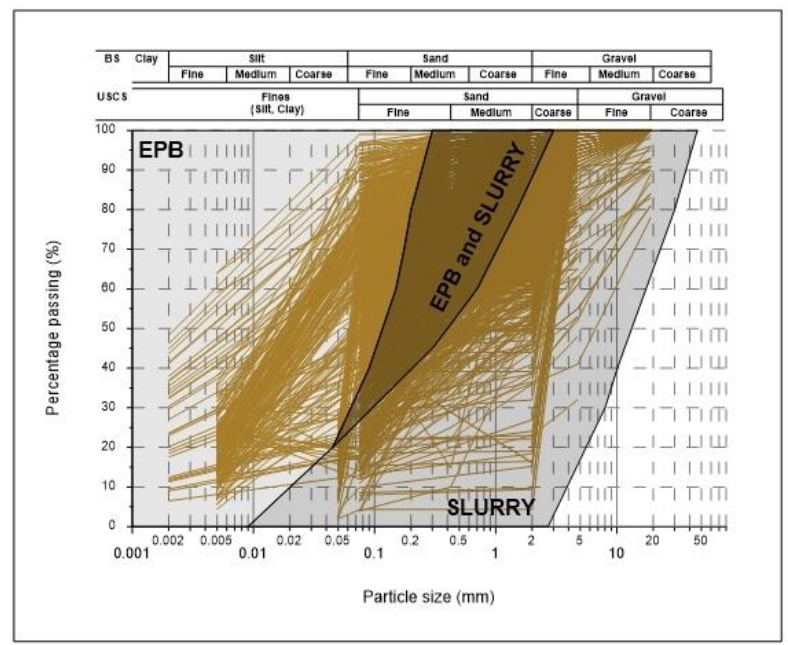

Figure 8 - Grading curves of Neogene deposits of the Central part and EPBM and Slurry TBM suitability limits.

\subsubsection{Permeability tests}

Figure 9 demonstrates the values of permeability of the Neogene deposits of central part. The prevalence of Maag tests is characteristic of the persistence of low permeability formations. The majority of the measurements (95\%) ranged between $10^{-8}$ and $10^{-6} \mathrm{~m} / \mathrm{sec}$ due to the formation of Neogene deposits. They primarily consist of moderately dense to very dense, and stiff to hard materials, which in many cases shows very small values of permeability that can be classified as impermeable. 


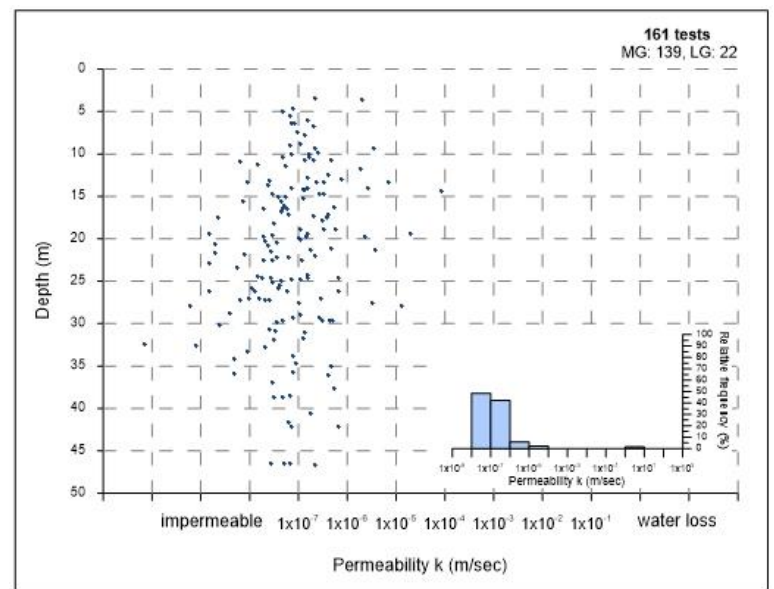

Figure 9 - Distribution charts of in situ permeability tests for the Neogene deposits of the Central part of the studied area.

\subsubsection{Sticky behaviour of formations}

Some types of cohesive soils, have the tendency to develop sticky behaviour. This behaviour affects all types of machines which are applied in a closed mode. Despite the fact that it is not a basic selection criterion, the tendency of the soils to stickiness has to be considered. The graph in Figure 10 is based on the published study of GEODATA (1995) for the Athens Metro Line 3 extension. This graph shows the relationship between the ratio of natural moisture content to plastic limit and the plasticity index. It also demonstrates the tendency of soils to develop sticky behaviour (low, medium, high). The place of the various points, determine the behaviour of the soils.

At this graph, 658 data from the Neogene deposits of the Central part are projected. The evaluation of this diagram shows that the majority of measurements ( 77\%) do not develop sticky behaviour, while only $6 \%$ is characterized by high sticky behaviour.

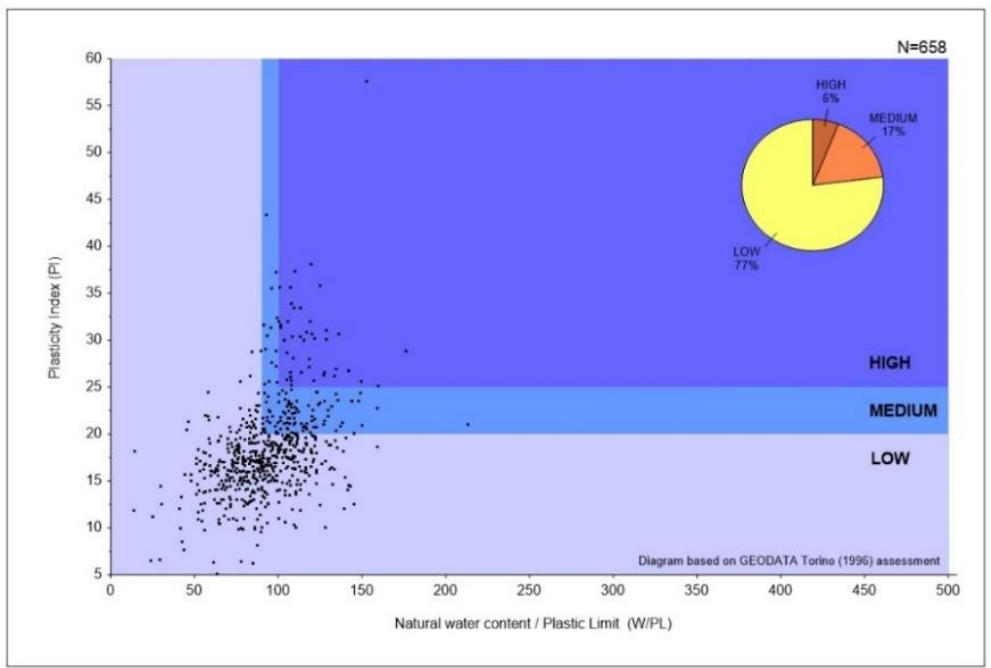

Figure 10 - Sticky behavior of Neogene deposits of the Central part of the studied area (based on the Geodata-Torino, 1995 classification). 


\section{Conclusions}

The present paper studies the engineering geological conditions in Thessaloniki basin, managed and assessed in a well-structure database. The purpose of that process here is to evaluate the geological response and geotechnical behaviour of the quaternary and neogene formations in underground works. The incorporated parameters in this study are standard penetration tests (SPT), uniaxial compressive strength (qu), Atterberg limits, groundwater level, permeability tests and particle size analyses.

The central part of the wider study area of Thessaloniki is generally formed by hard to stiff clays of high strength parameters and good geotechnical behavior. From the evaluation of physical and mechanical parameters it was shown that an EPB TBM is expected to perform efficiently in the largest part of the alignment. Even in specific areas where the presence of coarser materials is high, an EPBM with the use of appropriate mode is the most effective.

\section{Acknowledgments}

We would like to thank the Central Laboratory of Public Works, Geognosi S.A. as well as Attiko Metro S.A. for the data provided.

\section{References}

Becker, C., 1995. Choice between EPB and Slurry shield, selection criteria by practical examples, Proc. Rapid Excavation and Tunneling Conference, San Francisco, 479-492.

Geodata, S.P.A, 1995. Feasibility study for tunneling method for Attiko Metro extension of line 3 to Egaleo, Part A: Review of alternative construction methods, Torino, Italy.

Guglielmetti, V., Grasso, P., Mahtab, A. and Xu, S., 2008. Mechanized tunneling in urban areas, design methodology and construction control, Geodata S.p.A., Turin, Italy.

I.G.M.E., 1978. Geological map of the wider Thessaloniki area, Scale 1:50.000.

Kiratzi, A., Chatzipetros, A., Papathanassiou, G. and Roumelioti, Z., 2014. Simulation of ground failures in the broader urban area of Thessaloniki, Proceedings of the 7th Hellenic Conference of Geotechnical Engineering, Athens, 5-7.

Kokkala, A., 2015. An engineering geological database for Thessaloniki basin with tunnel applications, Aristotle University of Thessaloniki, MSc thesis.

Marinos, P.G., Novack, M., Benissi, M., Panteliadou, M., Papouli, D., Stoumpos, G., Marinos, V. and Korkaris, K., 2008. Ground Information and Selection of TBM for the Thessaloniki Metro, Greece Environmental and Engineering Geoscience, XIV/1, 17-30.

Marinos, V., Prountzopoulos, G., Fortsakis, P., Koumoutsakos, D., Korkaris, K. and Papouli, D., 2013. Tunnel Information and Analysis System: A Geotechnical Database for Tunnels, Geotechnical and Geological Engineering, 31(3), 891-910.

Mountrakis, D., 2010. Geology and Geotectonic evolution of Greece, Thessaloniki, University Studio Press.

Rick, P., TBM Design Considerations: Selection of Earth Pressure Balance or Slurry Pressure Balance Tunnel Boring Machines, Lovat Inc.

Rozos, D., Apostolidis, E. and Hadzinakos, I., 2004. Engineering-geological map of the wider Thessaloniki area, Greece, Bulletin of Engineering Geology and the Environment, 63(2), 103-108.

Rozos, D., Apostolidis, E. and Hadzinakos, I., 1998. Engineering-geological map of the wider Thessaloniki area, Scale 1:25.000, I.G.M.E.

Zervopoulou, A., 2010. Neotectonic faults in the urban site of Thessaloniki in relation to the soils foundation, Aristotle University of Thessaloniki, Phd thesis. 